\section{CORRECTION}

View Article Online

View Journal I View Issue

\section{D) Check for updates}

Cite this: Food Funct., 2021, 12, 8208

\title{
Correction: Bilberry anthocyanin improves the serum cholesterol in aging perimenopausal rats via the estrogen receptor signaling pathway
}

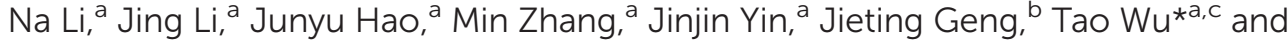 \\ Xiaoling Ly ${ }^{\star a}$ \\ Correction for 'Bilberry anthocyanin improves the serum cholesterol in aging perimenopausal rats via the \\ estrogen receptor signaling pathway' by Na Li et al., Food Funct., 2019, 10, 3430-3438, DOI: 10.1039/ \\ C9FO00639G
}

DOI: $10.1039 / \mathrm{d} 1 \mathrm{fo} 90064 a$

The authors regret that an incorrect grant number was given in the acknowledgements section of the published article. The corrected section should read:

This work was supported by the Natural Science Foundation of Tianjin [18JCQNJC06000], Tianjin Science and Technology Fund Planning Project [18ZYPTJC00020], Tianjin One Belt and One Road Technological Innovation Project [18PTZWHZ00080] and National Natural Science Foundation of China [31501475].

The Royal Society of Chemistry apologises for these errors and any consequent inconvenience to authors and readers.

\footnotetext{
${ }^{a}$ State Key Laboratory of Food Nutrition and Safety, Tianjin University of Science \& Technology, Tianjin 300457, China. E-mail: wutaoxx@gmail.com, lxling@tust.edu.cn; Fax: +86-22-60912431; Tel: +86-22-60912431

${ }^{b}$ Department of Food Science and Technology, Tokyo University of Marine Science and Technology, Konan 4-5-7, Minato-ku, Tokyo 108-8477, Japan

${ }^{c}$ Beijing Advanced Innovation Center for Food Nutrition and Human Health, Beijing Technology \& Business University, Beijing, China. E-mail: wutaoxx@gmail.com; Fax: +86-22-60912430; Tel: +86-22-60912430
} 